\title{
How Body Feedback Influences Consumers' Evaluation of Products
}

\author{
Jens Förster \\ International University Bremen
}

\begin{abstract}
Two experiments explored the effect of unobtrusively induced expressions of approach and avoidance on consumers' evaluation of well-known products. In Study 1, valenced objects were presented moving horizontally or vertically on a screen, thereby inducing either head shaking or head nodding. Objects were also presented without movement. Induced nodding led to more favorable evaluations of positively valenced products but did not affect the evaluation of negatively valenced ones. Similarly, head shaking led to more unfavorable evaluations of negatively valenced products but did not affect the evaluation of positive ones. In Study 2, participants evaluated positively valenced products more favorably when they flexed their arms while making the evaluation and evaluated negatively valenced products more unfavorably when they extended their arms during evaluation. However, arm flexion had no effect on evaluations of negative products, and arm extensions had no effect on evaluations of positive ones. Participants' willingness to buy the products followed a similar pattern. The theoretical implications and the applications of these body feedback effects are discussed.
\end{abstract}

Expressive behaviors are typically viewed as a reaction to stimuli in the external world. People nod when they are in agreement and they embrace when they like each other. However, behavior can influence the way we perceive people and objects. Research on the impact of body feedback (for reviews, see Adelman \& Zajonc, 1989; Förster, 1995; Izard, 1990) has repeatedly demonstrated that unobtrusively induced expression patterns can unintentionally influence cognition, emotion, and behavior. These results have provided strong evidence that affective or experiential cues have a direct influence on judgments, including attitudes (see, for example, Bodur, Brinberg, \& Coupey, 2000; Breckler, 1984; Haugtvedt, 1997; Herr, 1995; Miniard \& Barone, 1997; Reed, Wooten, \& Bolton, 2002; Schwarz, 1997; Schwarz \& Strack, 1991; Strack \& Neumann, 2000; Zajonc \& Markus, 1982).

In the following studies, we investigate if the evaluation of well-known consumer goods can be influenced by unobtrusive expression patterns such as nodding or shaking the head, or by even more rudimentary components of approach and avoidance behavior, specifically, arm flexion and arm extension.

Requests for reprints should be sent to Jens Förster, International University Bremen, Campus Ring 1, P.O. Box 750561, 28725 Bremen, Germany. E-mail: j.foerster@iu-bremen.de

\section{THEORETICAL BACKGROUND}

Several experiments have shown that unobtrusively induced expression patterns influence participants' reported feelings (e.g., Larsen, Kasimatis, \& Frey, 1992; Stepper \& Strack, 1993; Zajonc, Murphy, \& Inglehart, 1989). For example, participants feel pride more intensely if they experience positive feedback while maintaining a positive, upright body position than if they receive the same feedback while in a negative, slouched position (Stepper \& Strack). Body feedback can also influence judgments of external stimuli (e.g., Strack, Martin, \& Stepper, 1988; Strack \& Neumann, 2000). In the classic "pen study" by Strack et al. (1988), participants who held a pen with their teeth (which activates the zygomatic muscles used for smiling) rated cartoons to be funnier than participants who held a pen with their protruding lips (which inhibits a smiling expression).

Moreover, people's evaluations of new or unknown objects and judgments of strangers are influenced by rudimentary components of approach and avoidance behavior (e.g., Cacioppo, Priester, \& Berntson, 1993; Förster, 1998). In Cacioppo et al.'s experiment, for example, participants performed either arm flexor contraction (by pressing their palms upwards on the back of a tabletop) or arm extensor contraction (by pressing their palms downward on it; see Priester, Cacioppo, \& Petty, 1996). According to the authors, the body 
feedback produced by arm flexion is associated with approaching positive stimuli, whereas the feedback produced by arm extension is associated with avoiding negative stimuli (see also, Förster, 1998, 2003; Förster, Higgins, \& Idson, 1998; Förster \& Strack, 1997, 1998; Neumann \& Strack, 2000). This hypothesis is based on the learning-theoretical notion that over the course of a lifetime, arm flexion (the motor action is directed toward the self) is repeatedly associated with acquiring or consuming desired objects (i.e., approach motivation), whereas arm extension (the motor action is directed away from the self) is repeatedly associated with rejecting undesired objects (i.e., pushing an object away). In a series of experiments, Cacioppo et al. showed that unknown Chinese ideographs were rated more positively when participants flexed their arms during evaluation than when they extended their arms during evaluation.

Förster (1998) extended these results, showing that even evaluations of strongly positive (attractive) and strongly negative (unattractive) photographs of young unknown men were affected by arm flexion and arm extension. Here, however, arm flexion led positive stimuli to be judged more favorably than both arm extension and no arm movement but had no influence on judgments of negative stimuli. Similarly, arm extension only affected judgments of negative stimuli. Thus, it seems that with novel valenced stimuli (i.e., strangers), movements must be congruent with the valence of the stimulus to have an effect.

What has been lacking in this domain is evidence that body feedback can influence individuals' judgments of stimuli toward which they have strong previously formed attitudes. For example, consumer goods to which one has been frequently exposed over a long period of time are likely to acquire strong evaluative meaning (e.g., "My favorite gummy bears are those from Haribo," or "I hate beef lung"). Evaluations of such products may be easily retrieved from memory (see Fazio, Chen, McDonel, \& Sherman, 1982), making them unsusceptible to situational or affective influence. Although the polarity of the attitude is stable (e.g., "I don't like the politician;" see Bennett, 1975; Bishop, Hamilton, \& McConahay, 1980), its strength might become exaggerated or diminished as a result of informational or affective input (e.g., "I despise him even more because of this scandal" or "I love him even more for this decision").

To test this general notion, Experiments 1 and 2 investigated the impact of body patterns on judgments of well-known objects with extreme valence. More specifically, names of products were used for which people have strong attitudes, such as favorite candy bars or commonly disliked food such as "beef lung." In Experiment 1, we manipulated the direction of head movement (i.e. head nodding and shaking), and in Experiment 2, we used arm flexion and arm extension to induce body feedback. Because some psychological models and processes can predict body feedback effects for unknown objects, let us now see whether they can predict effects for well-known objects.

\section{Self-Perception}

One of the most prominent models of how the body can influence evaluation is self-perception (Bem, 1972; for reviews, see Fazio, 1987; Olson \& Hafer, 1990). A woman who is asked to smile while evaluating a product might observe her behavior and use a "if I am smiling, the product must be good" heuristic as a basis for judging the product. Self-perception theory assumes that people consciously make inferences about their behavior and perceptions. Although such mechanisms clearly operate in many situations, this explanation can be ruled out when the meaning of the expression patterns is disguised. In most of the experiments on body feedback, participants are unaware of the manipulation and its influence. A classic example is the pen study by Strack et al. (1988) in which participants were asked to hold a pen between their lips or teeth under the cover story of an investigation of "how physically challenged people could answer a questionnaire." Facial feedback effects in this study were found although participants did not consciously realize that they were expressing a smile or frown. In most of the experiments on body feedback, participants are unaware of the manipulation and its influence. Moreover, when feelings are measured via self-reports, they often fail to mediate judgments, again excluding self-perception as the underlying mechanism. By ruling out the effects of semantic meanings that are potentially given to bodily experiences, one can also exclude representational models, which assume that feelings are cognitively represented (Bower, 1981) as an explanation for body feedback effects (see Barsalou, Niedenthal, Barbey, \& Ruppert, in press; Förster, 1995, for a discussion).

\section{Self-Validation}

Briñol and Petty (2003) have suggested a self-validation process whereby body patterns of agreement (nodding) and disagreement (head shaking) can influence evaluation. They contended that nodding could enhance confidence in related thoughts because it signals that one's thoughts are valid, whereas head shaking could reduce this confidence by suggesting that one's thoughts are incorrect or flawed. This account predicts that when participants' thoughts are favorable during a persuasive message, nodding will enhance persuasion by increasing confidence, and head shaking would reduce it by signaling disapproval. When participants' thoughts are unfavorable, however, the reverse should be true; that is, shaking should reduce confidence by signaling disapproval, causing the person to discount his thoughts, which then decreases the impact. In their studies, undergraduate students were exposed to a proposal (e.g., requirement to carry personal identification cards on campus) while they were either nodding or shaking their heads. The information contained either strong arguments (e.g., personal security is improved) or weak ones (e.g., some security guards felt that they would have more time for lunch with the new system in place). When the arguments were strong, "nodders" had more favor- 
able opinions toward the proposal than "shakers." When the arguments were weak, however, "nodders" reported less favorable opinions than did "shakers."

The different effects of body feedback on responses to strong and weak arguments can be explained if people who encounter these arguments spontaneously perceive them to be either strong or weak and then use their body feedback as indications that these perceptions are valid. Thus, if they interpret the arguments as strong, nodding may confirm this interpretation, increasing their influence. If the arguments are interpreted as weak, however, nodding may confirm this perception, leading the arguments to have even less of an effect than they otherwise would. In contrast, shaking should have the opposite effect in the two conditions. This interpretation, however, applies only to responses to persuasive communications, and is not relevant to judgments of objects for which a strong prior attitude exists and are presented out of any persuasion context.

A self-validation might nevertheless be viable. Nodding while thinking about a desirable product (e.g., a dish of one's favorite ice cream) could signal that one's spontaneous reactions to the product are valid and might initiate a search for confirming evidence (e.g., memory of nice taste and texture), leading to positive evaluations. In contrast, head shaking, could signal that one's reactions are invalid and could stimulate a search for counterarguments (e.g., ice cream is fattening and unhealthy). When thinking about disgusting food (e.g., kidneys), on the other hand, head shaking might signal that one's spontaneous negative reactions are invalid and induce a search for positive evidence (e.g., that the food contains important vitamins). Therefore, it might lead to a more positive evaluation than nodding. Although this "modified self-validation account" is plausible, however, it is restricted to expressions of agreement versus disagreement. Therefore, it cannot explain other body feedback effects, such as the ones with arm flexion versus arm extension. Moreover, Briñol and Petty (2003) did not find any evidence of differentially valenced thoughts in their studies, which rules out the effects of body feedback on information search.

\section{Conditioning}

Some researchers have suggested a classical conditioning approach via emotions or affect (see Cacioppo, Priester, \& Berntson, 1993; Tom, Petterson, Lau, Burton, \& Cook, 1991). Bodily reactions and stimulus features can become conditioned to a positive or negative evaluative response through learning - both the bodily reaction and the valence of the stimulus contribute to its overall evaluation. In one study, however, Priester et al. (1996) reasoned on the basis of their Elaboration Likelihood Model (Petty \& Cacioppo, 1981, 1986) that conditioning processes are more potent determinants of attitudes when elaboration likelihood is low. Rescorla and Wagner (1972) reasoned that the efficacy of conditioning is diminished by preexposure to condi- tioned stimuli. In line with this account, Priester et al. presented evidence that arm flexion and arm extension only affected novel stimuli (pronounceable nonwords) and not neutral, known words. These findings suggest that body feedback effects are less likely to influence judgments of well-known or valenced products than of unfamiliar, neutral ones. However, Förster (1998) challenged this view, showing influences of arm positions on attractive and unattractive strangers. Thus, neutrality of the stimulus is not a necessary condition for body feedback effects; it seems that a more specified model is needed to explain these divergent results.

Given that people use their subjective bodily reactions for judgment formation, one might speculate that the conditioned reactions to body feedback and the reactions stimulus features have additive effects. If this were true, evaluations of a positively valenced stimulus should be decreased by body feedback that signifies avoidance, whereas evaluations of a negatively valenced stimulus should be enhanced by feedback that signifies approach.

In Förster's (1998) study, however, no differences between control and incompatible conditions were found. It seems, therefore, that conditioning accounts need to be elaborated to explain the divergent results.

\section{Motor Compatibility}

To account for the effects of body feedback, we propose a conceptual-motor compatibility model. This model was initially developed to predict processing advantages of information that has the same valence as an expression pattern (Förster, 1995; Förster \& Strack, 1996; Neumann, Förster, \& Strack, 2003; for a review, see Barsalou et al., in press). Research in the area of perceptual-motor compatibility (for a review, see Alluisi \& Warm, 1990) shows that response selection is faster if the sensory modalities of stimuli and responses are compatible than if they are incompatible because the compatible information is relatively better encoded (see Greenwald, 1970). In natural situations, certain overt responses to stimuli frequently accompany covert reactions and, therefore, are likely to become associated with these responses through learning. For example, arm flexion is an approach reaction to subjectively positive information, whereas arm extension is an avoidance reaction to subjectively negative information. With repetition, such learned associations become virtually automatic, so that one may spontaneously elicit the other. Those reactions can be considered compatible. On the other hand, individuals can intentionally "bypass" covert reactions to stimuli. For example, they consume bitter-tasting medication, embrace and smile at a person they do not like, and try to avoid a temptation. Although these incompatible overt behaviors can be performed, they require more behavioral effort or processing capacity than behaviors that are compatible with one's covert reactions. Thus, participants are faster to push a lever away (avoid) than to pull it to- 
ward them (approach) in response to negative stimuli, whereas the reverse is true for positive stimuli (Chen \& Bargh, 1999).

Förster and Strack (1996) have demonstrated that valence-compatible stimuli are better encoded by using a paradigm employed by Wells and Petty (1980). They showed that participants who performed vertical head movements while listening to positive and negative words had better memory for the positive words than negative words, whereas the reverse was true for participants who performed horizontal head movements (Förster \& Strack, 1996, Experiments 1 \& 2 ). Because the head movements occurred only during the learning phase, the interactive influence between expressions and the valence of the stimuli was assumed to occur during encoding rather than during retrieval. To demonstrate that learning information incompatible with an expressive motor pattern requires more cognitive capacity than learning compatible information, participants in one experiment (Förster \& Strack, 1996; Experiment 3) performed a secondary task (placing pegs into holes on a board) while learning positive or negative words. Participants did worse on the secondary task when their head movements were incompatible with the words to be learned than when they were compatible. Later studies replicated these findings with approach and avoidance body postures (upright position vs. kneeling down; Förster \& Stepper, 2000).

The model can explain influences of expressions on neutral novel stimuli. Because the expression has been associated with either approach or avoidance, its affective meaning may be elicited automatically and may be misattributed to the novel stimulus (Schwarz \& Clore, 1983, 1998). Note that no inclination to approach or avoid is elicited by the stimulus itself, and so the expression provides the only information that can be used. In this case, approach behavior will lead to more favorable evaluations, and avoidance behavior will lead to less favorable evaluations.

When strong positive or negative affective reactions have become associated with a stimulus, however, different considerations arise. When both reactions are compatible, both affective reactions to the stimulus and the feedback elicited by the bodily movement may contribute to judgments. In these conditions, encoding is "easy," the two influences are hard to distinguish, and the evaluative responses combine. This influence is automatic (Förster, 1998). When the two sources of stimulation are incompatible, however, participants may be able to distinguish between relevant and irrelevant sources of information and, therefore, do not misattribute the behavior-induced subjective experience to the object they are judging. Experiencing a behavioral pattern that is incompatible with one's spontaneous reaction might interrupt the automatic influence of experiences on judgments. Behavioral information in these situations might be viewed as an inappropriate basis for the judgment (see Strack, 1992) and, therefore, might be discounted. In this case, no influence should occur.
Note that whereas the inferential component is a more conscious process, which can develop as a heuristic over time (e.g., "do not use your bodily experiences if your reaction is odd"), the subjective responses that are used as a basis for inference may be stimulated by factors of which participants are not clearly aware. This is the case in the body feedback experiments and in situations where people simply do not know that their behavior was influenced by external factors (e.g., seating arrangements that cause slouched postures).

The incompatibility experienced is presumably stronger when the items have extreme valence and are well-known. However, the same logic also applies to well-known neutral stimuli, which, according to the results by Priester et al. (1996), are not affected by expressions. For neutral or irrelevant stimuli, the spontaneous reaction is neither approach nor avoidance, so approach and avoidance manipulations might also be experienced as odd and become discounted.

\section{Summary}

Several mechanisms could potentially underlie the effects of body feedback. This research examines which of these mechanisms provides the best account of its effects on judgments of well-known products with strong valence. As we have noted, self-perception mechanisms might occur in some situations but cannot operate when people are unaware of the meaning of the body feedback they experience. A modified self-validation account could predict a crossover interaction between bodily expressions of approval and disapproval and the valence of the products, with positively valenced objects being evaluated more favorably in the context of expressions of approval and negatively valenced objects being evaluated more unfavorably in the context of expressions of disapproval. Compared to no movement control conditions, shaking should lead to less favorable evaluations for positive objects and nodding should lead to more favorable evaluations for negative objects. No effects of expressive patterns that are unrelated to approval or disapproval can be derived from this model. Conditioning accounts could predict a general effect of body positions that is independent of the type of product being evaluated. Finally, the motor-compatibility conceptualization also predicts more positive evaluations for positive objects when bodily expressions signal approach and more negative evaluations for negative objects when body feedback signals avoidance. When the body feedback is incompatible with the valence of the object being considered, however, this conceptualization implies that evaluations will not differ from those that are made in the absence of feedback.

These possibilities were evaluated in two experiments. In each study, participants, who were induced to mimic bodily expressions of approach or avoidance, evaluated verbal descriptions of desirable products (e.g., "Snickers," a popular candy bar) and negative objects (e.g., "beef lung," which is used as dog food rather than for human consumption in Germany, where the experiments took place). In Study 1, under- 
graduates were tested in a laboratory by presenting positive and negative objects on a screen that moved horizontally, vertically, or appeared stationary in the center of the screen. It was assumed that this would cause the participants to shake their heads, nod their heads, or adopt a nonspecific, static position. In Study 2, participants were asked to flex, extend, or rest their arms while evaluating objects that were motionless on the screen.

\section{EXPERIMENT 1}

\section{Method}

Stimulus material. To identify positive and negative well-known consumer goods, 10 research assistants at the University of Würzburg created a list of 100 types of food, containing, for example, well-known candy bars, cookies, and beverages, among others. These were presumably good or bad in valence for university students in general. In a pretest, the goods were rated by 96 participants on a scale from 1 (very negative) to 9 (very positive) with an extra option: "I do not know this product." From the data obtained, 13 products were taken for the actual study which were highly positive (ranging from $M=6.12$ to $M=6.90$ ) or highly negative (ranging from $M=1.37$ to $M=2.87$ ) and known by everybody in the pretest. The positive products were as follows: Snickers Candy Bar, Landliebe Milk, Chio Potato Chips, Evian Table Water, Milka Chocolate, Dr. Oetker Pizza, and Haribo Gummy Bears. The negative products were as follows: Berentzen Schnaps, beef lung, Verpoorten eggnog, Aldi River Cola, lard, and pig tongue.

Participants and design. Forty-three undergraduate students at the University of Bremen were asked to participate in an "experimental battery, testing several psychological hypotheses." Participants, tested individually, were randomly assigned to conditions and paid 14 Euros (about U.S. $\$ 12$ ) for their time. The experiment was a $3 \times 2$ within-subjects design involving movements (vertical vs. horizontal vs. motionless) and object valence (positive vs. negative). In additional analyses, the starting position of the movements (up or down, left or right) was added as a factor to control for its influence on the results.

Procedure. After performing a series of short tasks pertaining to other, unrelated experiments, participants were asked to take part in a study on product evaluation. Individually, they sat in front of a screen, $146 \mathrm{in.}(370 \mathrm{~cm})$ in length and 73 in. $(185 \mathrm{~cm})$ in height and were asked to evaluate the objects that appeared on it. The distance between the seat and the screen was about 71 in. $(180 \mathrm{~cm})$. Participants were informed that the stimuli would be projected on the screen and would move in different directions to ensure that the items would receive full attention.
Participants were given a booklet, on the first page of which they were asked to report their current mood ("How do you feel right now?") on a scale from 1 (very good) to 9 (very good). After the mood questionnaire was completed, presentation of the objects (e.g. beef lung, Snickers, etc.) began.

Participants were instructed to attend to the entire presentation of an object before making the evaluation (i.e., mark the judgment on the questionnaire after the presentation, during the interstimulus interval). All 13 objects were presented as the product name (i.e., the word Snickers instead of a picture of a Snickers bar) to each participant once in random order via PowerPoint. By random assignment, 4 of the 13 objects were presented with vertical movement, 4 with horizontal movement, and 5 with no movement. In the movement conditions, the starting point for the movement was equally divided (i.e., two of the vertical movement presentations started at the top and two at the bottom; two of the horizontal movement presentations started at the left and two at the right; this was also randomly assigned). To induce a natural sequence leading to nodding and shaking, the movements (up and down; down and up, right then left; left then right) were repeated four times for each object, with each movement lasting approximately $4.5 \mathrm{sec}$. Under no-movement conditions, the object appeared continuously on the screen for $20 \mathrm{sec}$. Each presentation was announced by a “*******” signal that appeared on the screen for $3 \mathrm{sec}$. After the series of presentations of a given object, the screen was blank for 60 sec to allow for sufficient time to make the evaluations. These judgments were recorded on the second page of the questionnaire booklet, which contained two rating scales for each of the 13 target objects. Specifically, participants were told to indicate both their liking for the object along a scale from 1 (not at all) to 9 (very much) and how much they would like to buy it along a scale from 1 (I would never buy it) to 9 (I would like to buy it very much).

During the presentations, experimenters recorded the order of presentation of the object and their starting positions for each participant because the names of the objects did not appear on the questionnaire and all respective factors were randomly assigned. Additionally, experimenters rated how much participants moved their heads on a scale from 1 (very much) to 9 (not at all); the overall mean was $M=5.2$.

After having evaluated the objects, participants were given a second mood questionnaire, which was identical to the first. Finally, participants were asked to write down their speculations about purpose of the experiment and about the meaning of the induced head movement. No participant had any plausible hypothesis or realized the meaning of the expression patterns. Afterwards, the questionnaires were collected and a thorough debriefing took place.

\section{Results and Discussion}

Evaluation. The mean liking ratings are summarized in Table 1. Positive objects were evaluated more favorably $(M=$ 
TABLE 1

Mean Product Evaluations and Desire to Buy the Product as a Function of Product Valence and Presentation Conditions-Experiment 1

\begin{tabular}{llll}
\hline & \multicolumn{3}{c}{ Presentation Conditions } \\
\cline { 2 - 4 } & Vertical & Control & Horizontal \\
\hline Liking & & & \\
Positive stimulus & $7.00_{\mathrm{a}}$ & $6.21_{\mathrm{b}}$ & $6.30_{\mathrm{b}}$ \\
$\quad$ Negative stimulus & $2.74_{\mathrm{c}}$ & $2.45_{\mathrm{c}}$ & $1.50_{\mathrm{d}}$ \\
Desire to buy the product & & & \\
Positive stimulus & $6.05_{\mathrm{a}}$ & $4.71_{\mathrm{b}}$ & $4.40_{\mathrm{b}}$ \\
Negative stimulus & $1.78_{\mathrm{c}}$ & $1.95_{\mathrm{c}}$ & $1.41_{\mathrm{d}}$ \\
\hline
\end{tabular}

Note. Means with unlike subscripts differ at $p<.05$ (two-tailed $t$ tests).

6.51) than negative ones $(M=2.23), F(1,84)=1080.33, p<$ .0001 , and objects were evaluated more favorably if they moved vertically $(M=4.87)$ than if they did not move $(M=$ 4.33) or moved horizontally $(M=3.90), F(2,84)=12.67, p<$ .001 . However, the interaction of object valence and movement was significant, $F(2,84)=3.73, p<.03$, and in the form predicted by the motor-compatibility account. Vertical presentation of positive products (which induced nodding) increased participants' liking for the products relative to control (no-movement) conditions, $t(42)=3.33 ; p<.003$, whereas horizontal presentation (which induced shaking) had no effect on liking for these products compared to the control group, $t(42)<1$. On the other hand, horizontal presentation deceased liking for negative products relative to no-movement conditions, $t(42)=3.44, p<.002$, whereas vertical presentation did not significantly affect evaluations of these products compared to the control group, $t(42)<1$. Thus, the hypothesis that head movements affect evaluation when the stimulus valence and head movement match was confirmed.

Desire to buy the product. Correlations between liking and desire to buy, computed separately within each experimental condition, ranged from .587 to .677 for favorable products and from .766 to .809 for unfavorable ones. The effects of experimental variables on the desire to buy are shown in the bottom half of Table 1. Participants reported greater desire to purchase positively valenced products than negatively valenced ones $(M=5.05$ vs. $M=1.71), F(1,86)=$ $383.91, p<.001$. Moreover, they reported greater desire to purchase if they had moved their head vertically $(M=3.91)$, and less desire to purchase if they had moved their head horizontally $(M=2.90)$, than under control conditions $(M=$ $2.90), F(2,86)=12.27, p<.001$. However, the interaction of presentation conditions and stimulus valence was also significant, $F(2,86)=7.65, p<.001$, and of the nature predicted. That is, vertical presentation increased the desire to buy positive products compared to the control group, $t(42)=3.85, p<$ .0001 , whereas the effect of horizontal presentation was not significant, $t(42)=1.00$. Similarly, horizontal presentation decreased desire to buy negative objects compared to the control group, $t(42)=2.20, p<.04$, whereas vertical presentation did not affect it significantly, $t<1$.

Additional analysis. Because some of the items appeared from the top and some from the bottom, as well as some from the right side and some from the left side, it seemed possible that these differences could have modified the effects. Some movements might have been more familiar to participants (because of reading directions from left to right) or might have had a positive semantic meaning. For example, there is a German proverb saying, "Alles Gute kommt von oben (All the goods things come from above)." In fact, however, this was not the case; additional analyses in which the two different starting positions of presentation as additional factors revealed no significant effects of these factors.

Mood. Correlational analyses with general mood before and after the presentation were conducted with each of the measures depicted in Table 1 to see whether mood could have produced the effects. There were no significant correlations between mood and any of the measures.

Summary. In sum, the results provide support for the motor compatibility model. When the motivational orientation implied by participants' head movements and target valence are compatible, judgments and behavior became more extreme. When they were incompatible, however, no significant effects of head movements on judgments of well-known products were observed. Mood did not mediate the effects. Because the results were strong, another experiment was conducted with even more subtle approach and avoidance expression patterns, namely arm flexion and extension. This experiment not only tested the limits of motor compatibility effects, but it showed that body feedback is a general principle that operates during evaluation and is not restricted to head movements alone.

\section{EXPERIMENT 2}

\section{Method}

Participants and design. Ninety-four first-year Würzburg psychology undergraduates were tested during their first lecture in "motivation psychology." They were asked to participate in an experiment on marketing research and were informed that they could choose not to participate. Ten participants did not complete the questionnaire, so they were excluded from the analyses. Participants were randomly assigned to the conditions in the experiment, which had a $3 \times 2$ mixed-model factorial design, comparing Arm Positions (flexion vs. extension vs. control) between participants and Object Valence (positive vs. negative) within participants.

Procedure. Participants received a booklet similar to that of Experiment 1, including information on anonymity 
and demographic questions on the first page. After being seated, participants were told to place their nondominant hand in the way the experimenter demonstrated it to them. Instructions for hand placement did not include words such as up and down, to avoid semantic priming of positive or negative valence. Participants were either shown to place their nondominant arms on their laps (control group), with their palms pressed against the underside of the table (arm flexion), or with their palms pressing down on the tabletop (arm extension). This was introduced as an "experimental presentation" whose purpose would be unveiled later. Because it is somewhat strenuous to perform the positions over a longer period, participants were allowed to relax their arms when marking their evaluation on the questionnaire but were asked to resume the indicated arm position during presentation of each object. The second page was the evaluation questionnaire, containing the names of the objects and two rating scales for each object: "How much do you like X?" on a scale from 1 (not at all) to 9 (very much), and "How much would you like to buy X?" from 1 (I would never buy it) to 9 (I would like to buy it very much).

The 13 products were projected on the screen of the lecture hall, again in a PowerPoint presentation. In contrast to Experiment 1, however, items always appeared for $25 \mathrm{sec}$ each in the middle of the screen. The items were presented only once and participants were asked to evaluate each single item directly after, but not during, its presentation. Because the experiment was conducted in a group, the order was consistent for all participants. As in Experiment 1, participants had $60 \mathrm{sec}$ between presentations to make their evaluation. The third page of the booklet contained the mood questionnaire and a question about the effortfulness of the arm position ("How effortful was the arm position?") on a scale from 1 (not effortful at all) to 9 (very effortful), and the fourth page asked participants to speculate about the outcome, the purpose of the experiment, and the meaning of the arm positions. No participant voiced any relevant hypotheses or correctly described the meaning of the arm positions. After having filled out the booklet, participants were thoroughly debriefed, and the implications of the research were intensively discussed in class.

\section{Results and Discussion}

Several mixed factorial measures analyses were conducted with each of the dependent variables.

Evaluation. As can be seen from Table 2, the pattern from Experiment 1 was replicated with arm positions. In general, positive products were evaluated more favorably than negative ones, $F(1,81)=1623.77, p<.0001$, and under arm flexion, objects were rated more positively $(M=5.17)$ than in the control condition $(M=4.49)$ or the arm extension condition $(M=4.20), F(2,81)=22.74, p<.0001$. These two effects were further qualified by a highly significant interaction between the two factors, $F(2,81)=13.54, p<.0001$. Arm
TABLE 2

Mean Product Evaluations and Desire to Buy the Product as a Function of Product Valence and Arm Position-Experiment 2

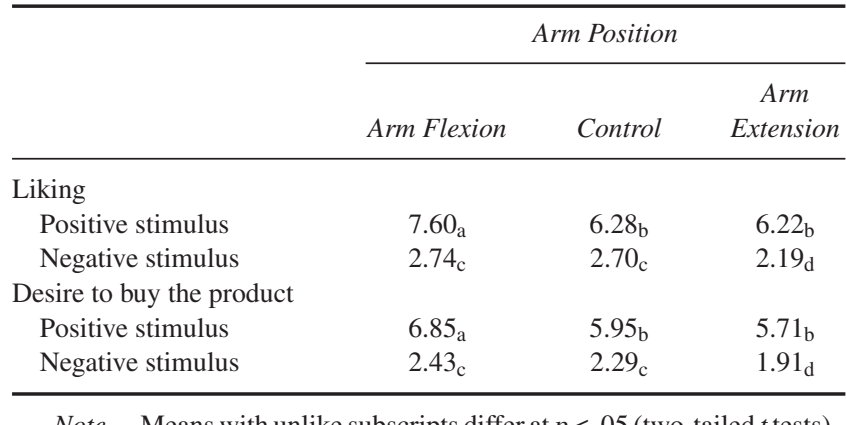

flexion increased evaluations of positively valenced products relative to control conditions, $t(81)=7.10, p<.0001$, whereas arm extension had no effect on liking for these products. On the other hand, arm extension decreased liking for negatively valenced products relative to control conditions, $t(81)=2.49, p<.02$, whereas arm flexion did not affect judgments of these products.

Desire to buy the product. Again, the desire to buy and the liking measures were positively correlated for positive objects with coefficients ranging from .614 to .790 and for negative objects with coefficients ranging from .795 to .898 . The mean ratings are summarized in Table 2 and match the pattern of the liking ratings. There was a main effect of valence, $F(1$, $81)=1496.31, p<.0001$, and a main effect of arm positions, $F(2,81)=22.97, p<.0001$; the latter again indicating that ratings were both higher when participants flexed their $\operatorname{arms}(M=$ 4.64) and lower when they extended their arms $(M=3.81)$ compared to the control conditions $(M=4.12)$ The interaction of object valence and arm position was also significant, $F(2$, $81)=5.26, p<.01$. Arm flexion increased the desire to buy positively valenced products relative to control conditions, $t(81)=$ $4.96, p<.0001$, whereas arm extension did not, $t(81)=1.34 ; p$ $>$.19. Similarly, arm extension decreased desire to buy negative objects relative to control conditions, $t(81)=2.18, p<.04$, but arm flexion did not, $t<1$.

Mood and effort. Because arm positions were tested comparing participants, two univariate analyses were conducted for the mood and the effortfulness of the position ratings to see whether they were affected by the manipulation. This, however, was not the case: mood did not vary over conditions $(6.17,6.07$, and 6.15 , under arm flexion, control, and arm extension conditions, respectively), $F<1$, and the arm positions did not differ in their effortfulness $(4.97,3.79$, and 4.81, respectively), $F(2,81)=2.44, p>.09$.

Correlational analyses with general mood and effort were conducted with each of the measures depicted in Table 2 to see whether these feelings could have accidentally mediated the effects. There was only one significant positive correla- 
tion found between evaluation of negative objects and effort of arm position when participants flexed their arms, $r=.492$, $p=<.008$, and between desire to buy negative objects and effort, when participants flexed their arms, $r=.452, p<.015$. These unpredicted correlations must be replicated in future research before they can be taken seriously. In general, it seems justifiable to conclude that feelings and mood do not predict the pattern of results we observed.

\section{GENERAL DISCUSSION}

The results of the two experiments show that when an induced approach or avoidance expression pattern is compatible with the valence of an object, evaluations and the desire to buy the product are affected. When the expression pattern and valence are incompatible, the evaluation is unaffected. Evaluations of positively valenced products were more favorable when approach behavior was induced, and evaluations of negatively valenced products were more unfavorable when avoidance behavior was induced. However, when the approach and avoidance expression patterns are incompatible with the valence of the object, they do not affect evaluation. In Experiment 1, approach and avoidance were induced by horizontal or vertical presentation of valenced objects, which presumably elicited head nodding and shaking. In Experiment 2, however, the arm positions of arm flexion (approach) and arm extension (avoidance) were used. Both experiments provided evidence for a compatibility model of body feedback on evaluation, predicting that valenced objects are more likely to be affected by compatible bodily expression patterns than by incompatible ones (see Förster, 2000; Förster \& Strack, 1996; Neumann et al., 2003).

The results extend existing research on body feedback demonstrating that even well-known consumer goods can be affected by expression patterns. Furthermore, the results show that effects of expression patterns are not restricted to neutral stimuli, such as Chinese ideographs, or to unknown targets such as unfamiliar persons. A classic self-perception model cannot account for the results because inferences on the meaning of the expression patterns were ruled out by using a cover story and the fact that no participant was aware of the meaning of the expression patterns. However, the motor compatibility model suggests that people draw inferences from situations of incompatibility, which could be regarded as a self- perception mechanism as well. In this case, such inferences could be based on experiences produced by the incompatible situation or on the mere realization that something is wrong. In our studies, however, we did not find any evidence for differences in mood. Further research is needed to explore possible inferential bases of these effects.

Conditioning models could account for the effects in compatible conditions, assuming additive effects of bodily experiences and valence of the information. To explain the lack of a difference between the control and the incompatible condi- tions, however, further processes must be assumed. Again, the data challenge theories that predict influences of bodily patterns on novel stimuli alone. Our results clearly show that novelty is not a necessary condition for these effects to occur.

The modified self-validation model predicts a difference between evaluation of incompatible objects (approach: negative; avoidance: positive) compared to control groups, which did not occur. Moreover, this account is silent on the effects in Experiment 2, where no movements of approval or disapproval were manipulated. Thus, although the self- validation model can predict persuasion in the attitude domain, it cannot easily predict evaluation of objects that already have a strong subjective value.

Finally, the effects obtained here seem to be independent of general mood. Although some body patterns can presumably affect mood (Stepper \& Strack, 1993), this could not have been the psychological mechanism responsible for the results in the experiments discussed earlier. Instead, compatibility between the motivational direction and the valenced cue directly influenced participants' judgments.

Although the motor compatibility account can explain most body feedback effects in the literature, it seems to be at odds with the recent results by Briñol and Petty (2003). Why can weak arguments receive more favorable evaluations under head shaking as shown in their studies? One difference between Briñol and Petty's studies and this one might be that in their studies, participants were uncertain about the outcome of their decision, but in the studies discussed earlier, participants' general judgments were conclusive. Although undergraduate students might have a general opinion about student identification and privacy issues, the specific decision of whether to introduce an identification card, which they learn has obvious advantages as well as disadvantages, might elicit more uncertainty than the decision about whether one likes one's favorite candy bar. Self-validation might simply not be necessary in the latter case. Under these conditions, therefore, mechanisms proposed by the motor-compatibility model might apply. Note that the self validation account goes far beyond body feedback effects and is concerned with the impact of confidence on attitude change in general, which can be produced by a variety of manipulations (Petty, Briñol, \& Tormala, 2002). Thus, these results do not question the model in general; it is just that we failed to apply its logic to our data and that some interesting candidates for underlying mechanisms in the body feedback domain might require further clarification. More research is needed to show when which mechanism operates.

In addition, the results by Priester et al. (1996), in which influences of arm movements were found for neutral unknown stimuli but not for neutral words, might also seem to conflict with the compatibility model. Conditioning approaches cannot entirely exclude influences of bodily patterns on valenced and well-known information, because conditioning is automatic and should affect all kinds of stimuli approximately equally. Second, there is a difference between neutral stimuli that are known and those that are unfamiliar. 
In the case of novel stimuli, no reactions have been proceduralized, so participants might simply use their subjective reactions to the stimulus that were produced by the experimental manipulation. Neutral stimuli with which one is already familiar, on the other hand, could constitute a case of incompatibility, because one usually neither approaches nor avoids neutral or irrelevant stimuli. Consequently, no effects are predicted. This reasoning implies that the mechanisms for novel and neutral stimuli and for known and neutral stimuli are different.

These findings extend those from Förster (1998) in showing body feedback effects on semantic objects. Förster speculated that approach and avoidance patterns might "bias" perception or visual search when participants evaluate faces. Participants may search for the positive aspects in the faces when they are approaching it and they may search for the negative aspects when they are avoiding it. Because we used verbal stimuli, mechanisms that bias a visual search for valence-consistent information cannot explain these results. Furthermore, this account cannot explain the absence of a difference between the incompatible and the control conditions. To predict no effects for incompatible conditions, we assume that people might be better able to distinguish between relevant and irrelevant sources. This mechanism seems to be a much better candidate to explain the effects in Förster's studies. Further research must clarify whether the inference mechanisms described in this article can explain results with visual stimuli as well or whether different mechanisms apply.

\section{Applications}

One could argue that these effects can influence consumers in the same way our participants were affected in the lab. However, it is clear from our studies that motor actions can be induced by different means that should also apply in the "real world." Experiment 1 shows that movements of objects, inducing approach and avoidance head movements, influence evaluations. These movements could theoretically influence judgments about stimuli on the Internet, in cinema ads, or in window displays. From this experiment, it seems that very subtle movements are sufficient to produce the effect. Additionally, research in the field of expression behavior shows that emotional stimuli can unconsciously lead to subtle motor expression patterns that can only be observed by electromyograph and not externally (Dimberg, Thunberg, \& Elmehed, 2000). As well, it could make a difference whether participants read information from the top to the bottom or left to right. Thus, it seems that movements of objects in advertisements should be given more attention. More research is needed to show when the effects occur in real life and to investigate the intensity of the movement required for influence to occur.

Although it might initially seem farfetched to consider manipulations of arm positions in everyday life, applications can be found for this method of induction. For example, the use of the classic computer mouse usually activates the arm extensor, which, as can be seen from Experiment 2, intensifies judgments of disliked objects. Thus, it might be useful to design a mouse that utilizes the underside of a tabletop as its base, inducing arm flexion. This would also be desirable from the user's perspective, because research has shown that arm flexion facilitates creative thinking, whereas arm extension inhibits it (Friedman \& Förster, 2000, 2002). It also seems to be worthwhile to investigate the difference between basket shoppers who activate the arm flexor and cart shoppers who activate the arm extensor. Our research would predict that the former would in general buy more than cart shoppers (if the size of the carts is equal). Although these considerations are highly speculative, they provide an interesting direction for future research.

Moreover, the experiments discussed earlier tested only two specific body patterns, leaving out hundreds of other approach and avoidance expressions. To give just one example, receiving positive feedback in an upright body position leads to feelings of pride compared to a slouched position. This could potentially be applied for use in designing office chairs or movie theater seats, for example. It has been shown that information compatible with the body postures is more easily encoded (Förster \& Stepper, 2000). Thus, placing desirable products at eye level might therefore be preferred over lower placing because the former could intensify positive judgments. Again, much more research is needed on this topic before we can make any further conclusions.

From the consumer's point of view, the experiments seem to paint a scary picture. How can one possibly control for such influences if used by the media, advertisers, and inventors? Here, social psychological theories provide some remedies for correcting unconscious influences. That is, correction of a judgment is possible if people know that they are influenced and if they know the direction of the influence (see Strack \& Hannover, 1996). If this is the case and if sufficient time and motivation are available at the moment of the judgment, individuals can recompute the judgment by collecting and reconsidering the information given or by adjusting their judgments on the scale (see Strack, Schwarz, Bless, Kübler, \& Wänke, 1993; and Strack \& Hannover for a comprehensive account of the correction processes). When the judgments are made rapidly and motivation is low, however, consumers cannot easily make corrections, and, therefore, they might still be influenced. For the sake of consumers, further research investigating how these influences can be counteracted may be invaluable.

\section{CONCLUDING REMARKS}

The studies add to the general constructivist notion of attitudes. Rather than merely reading attitudes from an internal meter, individuals' judgments can be influenced by subtle environmental and affective cues. Research has shown that attitudes are temporary constructions (Tesser, 1978; Tourangeau \& Rasinski, 1988; Wyer \& Hartwick, 1980; Zanna, 1990, to 
name only a few), but this malleability has certain limits. One may be unable to change a strong judgment from positive to negative or from negative to positive, but at the same time, one may exaggerate and intensify the valence of the attitude. This could have behavioral consequences. For example, learning that your annoying colleague just broke the copy machine might lead you to dislike him even more, and learning that your favorite, but a bit too pricey, car becomes "car of the year" might be enough to convince you to buy it. These findings show that even extremely subtle cues can lead to differences in people's preferences and inclinations to buy products. These notions, as well as the billions of other possibilities, convince us that research in this area is applicable not only for marketing and advertising, but even more important, for everyday life.

\section{ACKNOWLEDGMENTS}

This research was supported by a grant from the Deutsche Forschungsgemeinschaft (FO-244/6-1) to Jens Förster. I thank Maren Breuer, Kirils Jegorovs, and Joanna Styczynska, who served as experimenters. Special thanks go to Markus Denzler and Angie Nichols for invaluable discussions. Markus Denzler is also thanked for the organization of the studies. Angie Nichols and Kirils Jegorovs are thanked for editing the manuscript and for helpful comments.

\section{REFERENCES}

Adelman, P. K., \& Zajonc, R. B. (1989). Facial efference and the experience of emotion. Annual Review of Psychology, 40, 249-280.

Alluisi, E. A., \& Warm, J. S. (1990). Things that go together: A review of stimulus-response compatibility and related effects. In R. W. Proctor \& R. T. Gilmour (Eds.), Stimulus response compatibility: An integrated perspective (pp. 3-30). Amsterdam, The Netherlands: North Holland.

Barsalou, L. W., Niedenthal, P. M., Barbey, A. K., \& Ruppert, J. A. (in press). Social embodiment. In B. H. Ross (Ed.), The psychology of learning and motivation. San Diego, CA: Academic.

Bem, D. (1972). Self-perception theory. In L. Berkowitz (Ed.), Advances in experimental social psychology (pp. 1-62). New York: Academic.

Bodur, H. O., Brinberg, D., \& Coupey, E. (2000). Belief, affect, and attitude: Alternative models of the determinant of attitude. Journal of Consumer Psychology, 9, 17-28.

Bower, G. H. (1981). Mood and memory. American Psychologist, 36, 129-148.

Bennett, W. L. (1975). The political mind and the political environment. Lexington, MA: D. C. H.

Bishop, G. G., Hamilton, D., \& McConahay, J. B. (1980). Attitudes and nonattitudes in the belief systems of mass publics. Journal of Social Psychology, 110, 53-64.

Breckler, S. J. (1984). Empirical validation of affect, behavior, and cognition as distinct components of attitude. Journal of Personality and Social Psychology, 47, 1191-1205.

Briñol, P., \& Petty, R. E. (2003). Overt head movements and persuasion: A self-validation analysis. Journal of Personality and Social Psychology, 84, 1123-1139.

Cacioppo, J. T., Priester, J. R., \& Berntson, G. G. (1993). Rudimentary determinants of attitudes. II: Arm flexion and extension have differential effects on attitudes. Journal of Personality and Social Psychology, 65, 5-17.
Chen, M., \& Bargh, J. A. (1999). Consequences of automatic evaluation: Immediate behavioral predispositions to approach or avoid the stimulus. Personality and Social Psychology Bulletin, 25, 215-224.

Dimberg, U., Thunberg, M., \& Elmehed, K. (2000). Unconscious facial reactions to emotional facial expressions. Psychological Science, 11, 86-89.

Fazio, R. (1987). Self-perception theory: A current perspective. In M. P. Zanna, J. M. Olson, \& C. P. Herman (Eds.), Social influence: The Ontario symposium (Vol. 5, pp. 129-150). Hillsdale, NJ: Lawrence Erlbaum Associates, Inc.

Fazio, R., Chen, J., McDonel, E., \& Sherman, S. J. (1982). Attitude accessibility, attitude-behavior consistency, and the strength of the object-evaluation association. Journal of Experimental Social Psychology, 18, 339-357.

Förster, J. (1995). Der einfluß von ausdrucksverhalten auf das menschliche gedächtnis: Theoretische Überlegungen und experimente zи motor-kongruenzeffekten [The influence of expression behavior on human memory: Theoretical considerations and experiments on motor-congruency effects]. Bonn, Germany: Holos.

Förster, J. (1998). Der Einfluß motorischer Perzeptionen auf Sympathie-Urteile attraktiver und unattraktiver Portraits [The influence of motor perceptions on likeability judgments of attractive and unattractive portraits]. Zeitschrift für Experimentelle Psychologie, 45, 167-182.

Förster, J. (2000). Psychologische passung [Psychological compatibility]. Germany: Habilitation Universität Würzburg.

Förster, J. (2003). The influence of approach and avoidance motor actions on food intake. European Journal of Social Psychology, 33, 339-350.

Förster, J., Higgins, E. T., \& Idson, L. C. (1998). Approach and avoidance strength during goal attainment: Regulatory focus and the "goal looms larger effect." Journal of Personality and Social Psychology, 75, $1115-1131$

Förster, J., \& Stepper, S. (2000). Compatibility between approach/avoidance stimulation and valenced information determines residual attention during the process of encoding. European Journal of Social Psychology, 30, 853-871.

Förster, J., \& Strack, F. (1996). Influence of overt head movements on memory for valenced words: A case of conceptual-motor compatibility. Journal of Personality and Social Psychology, 71, 421-430.

Förster, J., \& Strack, F. (1997). Motor actions in retrieval of valenced information: A motor congruence effect. Perceptual and Motor Skills, 85, $1419-1427$

Förster, J., \& Strack, F. (1998). Motor actions in retrieval of valenced information II: Boundary conditions for motor congruence effects. Perceptual and Motor Skills, 86, 1423-1426.

Friedman, R. S., \& Förster, J. (2000). The effects of approach and avoidance motor actions on the elements of creative insight. Journal of Personality and Social Psychology, 79, 477-492.

Friedman, R. S., \& Förster, J. (2002). The influence of approach and avoidance motor actions on creative cognition. Journal of Experimental Social Psychology, 38, 41-55.

Greenwald, A. G. (1970). Sensory feedback mechanisms in performance control: With special reference to the ideo-motor mechanism. Psychological Review, 77, 73-97.

Haugtvedt, C. P. (1997). Beyond fact or artifact: An assessment of Fishbein and Middelstadt's perspective on attitude change process. Journal of Consumer Psychology, 6, 99-106.

Herr, P. M. (1995). Whither fact, artifact and attitude: Reflections on the theory of reasoned action. Journal of Consumer Psychology, 4, 371-380.

Izard, C. E. (1990). Facial expressions and the regulation of emotions. Journal of Personality and Social Psychology, 58, 487-498.

Larsen, R. J., Kasimatis, M., \& Frey, K. (1992). Facilitating the furrowed brow: An unobtrusive test of the facial feedback hypothesis to unpleasant affect. Cognition and Emotion, 6, 321-338.

Miniard, P. W., \& Barone, M. J. (1997). The case of noncognitive determinants of attitude: A critique of Fishbein and Middlestadt. Journal of Consumer Psychology, 6, 77-91.

Neumann, R., Förster, J., \& Strack, F. (2003). Motor compatibility: The bi-directional link between behavior and evaluation. In J. Musch \& K. C. 
Klauer (Eds.), The psychology of evaluation: Affective processes in cognition and emotion (pp. 371-391). Mahwah, NJ: Lawrence Erlbaum Associates, Inc.

Neumann, R., \& Strack, F. (2000). Approach and avoidance. The influence of proprioceptive and exteroceptive cues on encoding of affective information. Journal of Personality and Social Psychology, 79, 39-48.

Olson, J. M., \& Hafer, C. L. (1990). Self-inference processes: Looking back and ahead. In J. M. Olson \& M. P. Zanna (Eds.), Self-inference processes: The Ontario symposium (Vol. 6, pp. 293-320). Hillsdale, NJ: Lawrence Erlbaum Associates, Inc.

Petty, R. E., Briñol, P., \& Tormala, Z. E. (2002). Thought confidence as a determinant of persuasion: The self-validation hypothesis. Journal of Personality and Social Psychology, 82, 722-741.

Petty, R. E., \& Cacioppo, J. T. (1981). Attitudes and persuasion: Classic and contemporary approaches. Dubuque, IA: Brown.

Petty, R. E., \& Cacioppo, J. T. (1986). The elaboration likelihood model of persuasion. In L. Berkowitz (Ed.), Advances in experimental social psychology (Vol. 19, pp. 123-205). New York: Academic.

Priester, J. R., Cacioppo, J. T., \& Petty, R. E. (1996). The influence of motor processes on attitudes toward novel stimuli versus familiar semantic stimuli. Personality and Social Psychology Bulletin, 22, 442-447.

Reed, A., II, Wooten, D. B., \& Bolton, L. E. (2002). The temporary construction of consumer attitudes. Journal of Consumer Psychology, 12, 375-388.

Rescorla, R. A., \& Wagner, A. R. (1972). A theory of Pavlovian conditioning: Variations in the effectiveness of reinforcement and nonreinforcement. In A. H. Black \& W. F. Prokasy (Eds.), Classical conditioning II: Current research and theory (pp. 64-99). New York: Appleton-Century-Crofts.

Schwarz, N. (1997). Moods and attitude judgments: A comment on Fishbein \& Middelstadt. Journal of Consumer Psychology, 6, 93-98.

Schwarz, N., \& Clore, G. L. (1983). Mood, misattribution, and judgments of well-being: Informative and directive functions of affective states. Journal of Personality and Social Psychology, 45, 513-523.

Schwarz, N., \& Clore, J. (1998). Feelings and phenomenal experiences. In E. T. Higgins \& A. W. Kruglanski (Eds.), Social psychology, handbook of social principles (pp. 433-466). New York: Guilford.

Schwarz, N., \& Strack, F. (1991). Evaluating one's life: A judgmental model of subjective well-being. In F. Strack, M. Argyle, \& N. Schwarz (Eds.), Subjective well-being: An interdisciplinary perspective (pp. 27-47). Oxford, England: Pergamon.

Stepper, S., \& Strack, F. (1993). Proprioceptive determinants of emotional and nonemotional feelings. Journal of Personality and Social Psychology, 64, 211-220.
Strack, F. (1992). The different routes to social judgments: Experiential vs. informational strategies. In L. Martin \& A. Tesser (Eds.), The contruction of social judgments (pp. 249-275). Hillsdale, NJ: Lawrence Erlbaum Associates, Inc.

Strack, F., \& Hannover, B. (1996). Awareness of influence as a precondition for implementing correctional goals. In P. M. Gollwitzer \& J. A. Bargh (Eds.), The psychology of action: Linking cognition and motivation to behavior (pp. 579-596). New York: Guilford.

Strack, F., Martin, L. L., \& Stepper, S. (1988). Inhibiting and facilitating conditions of the human smile: A non-obtrusive test of the facial feedback hypothesis. Journal of Personality and Social Psychology, 53, 768-777.

Strack, F., \& Neumann, R. (2000). "The spirit is willing, but the flesh is weak": Beyond mind-body interaction in human decision-making. Organizational Behavior \& Human Decision Processes, 65, 300-304.

Strack, F., Schwarz, N., Bless, H., Kübler, A., \& Wänke, M. (1993). Awareness of the influence as a determinant of assimilation versus contrast. $E u$ ropean Journal of Social Psychology, 23, 53-62.

Tesser, A. (1978). Self-generated attitude change. In L. Berkowitz (Ed.), Advances in experimental and social psychology (pp. 408-448). New York: Academic.

Tom, G., Petterson, P., Lau, T., Burton, T., \& Cook, J. (1991). The role of overt head movement in the formation of affect. Basic and Applied Psychology, 12, 281-289.

Tourangeau, R., \& Rasinski, K. A. (1988). Cognitive processes underlying context effects in attitude measurement. Journal of Experimental Social Psychology, 25, 401-421.

Wells, G. L., \& Petty, R. E. (1980). The effects of overt head movements on persuasion: Compatibility and incompatibility of responses. Basic and Applied Social Psychology, 1, 219-230.

Wyer, R. S., \& Hartwick, J. (1980). The role of informational retrieval and conditional inference processes in belief formation and change. In L. Berkowitz (Ed.), Advances in experimental social psychology (pp. 241-284). Orlando, FL: Academic.

Zajonc, R. B., \& Markus, H. (1982). Affective and cognitive factors in preferences. Journal of Consumer Research, 9, 123-131.

Zajonc, R. B., Murphy, S. T., \& Inglehart, M. (1989). Feeling and facial efference: Implications of the vascular theory of emotion. Psychological Review, 96, 395-416.

Zanna, M. P. (1990). Attitude functions: Is it related to attitude structure? Advances in Consumer Research, 17, 98-100.

Received: September 2, 2003

Accepted: October 26, 2003 
Copyright of Journal of Consumer Psychology is the property of Lawrence Erlbaum Associates and its content may not be copied or emailed to multiple sites or posted to a listserv without the copyright holder's express written permission. However, users may print, download, or email articles for individual use. 